\title{
The Effects of Climate Change Phenomena on Cocoa Production in Malaysia
}

\author{
Ali Chizari ${ }^{1}$, Zainalabidin Mohamed ${ }^{2}$, Mad Nasir Shamsudin ${ }^{3}$, Kelly Wong Kai Seng ${ }^{4}$ \\ 1,2,3,4 Department of Agribusiness and Bioresource Economics, Faculty of Agriculture, UPM
}

Corresponding Author: Ali Chizari

\begin{abstract}
Climate change is arguably one of the most important factors influencing agricultural production in developing countries such as Malaysia. Therefore, it becomes important to explore the impacts of climate change on agricultural yield and production. Cocoa was brought to Malaysia for commercial planting in the 1950s. The cocoa industry grew to become the third major commodity crop in Malaysia after oil palm and rubber. In 2013, Malaysia became 28th among the Cocoa-producing countries in the world. The way forward requires increased understanding and awareness to cope with the interdependencies and interactions of natural resources and climate change, the vulnerabilities and interdisciplinary efforts. This study applied the autoregressive distributed lag (ARDL) co-integration approach over the periods $(1980-2014)$. There are two main methods including the Regional Climate Model $(R C M)$ which can reasonably produce appropriate projections that can be used for climate scenario generation in a country-scale. Based on this information, this study considered three scenarios: 1) First Scenario, Rainfall changes 2) Second Scenario, Temperature changes 3) Third Scenario, Scenario 1 and 2 simultaneously. Preliminary results from the Autoregressive Distributed Lag (ARDL) model applied indicated that despite the projected changes in the climate variables (temperature and rainfall), in scenario 1 (the projected changes (5\% increase) in rainfall), cocoa yield is expected to decline from 0.148 tonne per hectare $(t / h a)$ in 2015 to 0.143 t/ha in 2020. The average trend compared to the baseline is positive and expected to develop by $+3.83 \%$ annually. In scenario 2 (the projected changes (2\% increase) in temperature), cocoa yield is expected increase from $0.149 \mathrm{t} / \mathrm{ha}$ in 2015 to $0.155 \mathrm{t} / \mathrm{ha}$ in 2020. The average trend compared to the baseline is positive and expected to increase by $+1.76 \%$ annually. Similarly, in scenario 3 (the projected simultaneous changes $(+5 \%)$ and $(+2 \%)$ in rainfall and temperature respectively), cocoa yield is expected to increase from 0.154 t/ha in 2014 to 0.189 t/ha in 2020.
\end{abstract}

Keywords-Cocoa, Climate Change, ARDL, RCM, MCB.

\section{INTRODUCTION}

Cocoa was brought to Malaysia for commercial planting in the 1950s (Malaysia Cocoa Board (MCB), 1991). The cocoa industry grew to become the third major commodity crop in Malaysia after oil palm and rubber. In 2013, Malaysia became $28^{\text {th }}$ among the Cocoa-producing countries in the world (World Cocoa Foundation, 2015). Currently, Cote d'Ivoire, Ghana, and Indonesia are the three largest producers of cocoa bean (Department of Statistics Malaysia, 2016).

The Malaysian cocoa beans and cocoa products export continued to increase as it rose from about 600,000 tonne in 2000 to 5 million tonne on 2015 (Department of Statistics Malaysia and Malaysian Cocoa Board, 2016). In 2015, cocoa beans and cocoa products was the second food exports with RM4.1 million and currently Malaysia is the largest cocoa processors in Asia (Department of Statistics Malaysia, 2016).

Presently, cocoa is cultivated in Sabah and Sarawak with about 6,260 ha $(38.9 \%)$ and 6,020 ha $(37.4 \%)$ respectively. However, as the price of cocoa went down, numerous plantations moved to palm oil production. The smallholder producers also declined, though at a slower rate compared to the estate cocoa producers (MCB, 2014).

In $2014,95 \%$ of cocoa is grown mainly by smallholding plantations on an area estimated around 15 thousand hectares. The areas under cocoa declined by almost half from around 30 thousand hectares to 15 thousand hectares in just a decade. Unfortunately, the plantation under the state also dropped dramatically from about 11,000 hectares to less than 900 hectares during the same period (2004-2014) (MCB, 2015). However, a fall in the global price of cocoa from RM14,323.01per Metric tonne to RM10,770.30 in 2015 to 2016 had significant negative impact on the expansion of cocoa plantations, thus making many smallholders to either destroy or abandon their cocoa plantations for other crops such as pepper and oil palm (World Bank, 2016).

The production of cocoa beans follows almost the same pattern with the planted area. Sabah is the largest producer with about 59.7\%, followed by Peninsular Malaysia (33.4\%) and Sarawak (6.9\%) (MCB, 2015). During the period (1985-1996), Malaysia average annual 
production of cocoa beans peaked at around 180,000 tonne. However, it declined in subsequent years by almost $98.6 \%$ to 2,665 tonne in 2014.

Yield measures profitability and also represent one of the most vital monetary elements influencing the cost of production per ton of cocoa beans. At higher efficiency, the cost of production per ton of cocoa will be lower and vice versa. In this regard, efforts need to be made to improve efficiency so as to ensure profit maximization.

The Malaysian national yield in cocoa increased from $0.79 \mathrm{t} / \mathrm{ha}$ in 2004 to $1.3 \mathrm{t} / \mathrm{ha}$ in 2008 . However, in 2014 the yield was just $0.166 \mathrm{t} / \mathrm{ha}$. At these levels of national production efficiency, Malaysia can be considered the most profitable cocoa producer on the planet. Nonetheless, this level of national profitability is far lower than the hypothetical potential yield of $11 \mathrm{t} / \mathrm{ha}$ (Corley, 1967) and the feasible yields of somewhere around 2.0 and $6.8 \mathrm{t}$ /ha (MohdYusof et. al, 1998). Interestingly, the smallholder cocoa producers under the recovery program organized by the Malaysian Cocoa Board accomplished a substantial increase in yield from less than $0.5 \mathrm{t} / \mathrm{ha}$ to $2.07 \mathrm{t} / \mathrm{ha}$ (Ministry of plantation industries and commodities (MOPICO), 2014).

Climate changes have been affected on cocoa production like other commodities in the world. These changes are wide and depends on the place are different. Kenneth and Baba Insah in 2014 found that increasing temperature and decreasing rainfall have negative impact on the cocoa production. Martin Noponenin 2015 figure out that drought in Indonesia has led to higher seed mortality and higher mortality for younger trees that are vulnerable to diseases. Also, Justina O. Lawal and Leo A. Emaku found out that there is weak negative correlation for both rainfall and relative humidity on cocoa yield over the years (0.257 and -0.196$)$ respectively while positive correlation (0.595) was established for temperature on yield. Furthermore,NwaJesus Anthony Onyekuru and Rob MarchantYork (2016) demonstrated that the results show positive impact of precipitation during the spring and adverse impact in the summer and autumn are also in agreement with works on plantation agriculture in Nigeria (Fonta et al., 2011), on cocoa production in Nigeria (Lawal and Emaku, 2007), in African cropland (Kurukulasuriyer and Mendelsohn, 2008) and on Ethiopian Agriculture (Deressa, 2007). Therefore, the impact of the climate changes are too various and need to find in each specific place and as I already mention because of the great exercise in Malaysia in cocoa industry it is really important to investigate of this impacts on coca production and yield.
Finally, the impact on agriculture due to the threats and effects of climate change while large and serious, is therefore compelling and urgent. Not addressing the challenges and the urgency of collective actions is going to be catastrophic. The way forward requires increased understanding and awareness to cope with the interdependencies and interactions of natural resources and climate change, the vulnerabilities and interdisciplinary efforts.

Econometric Model is applied in this study simply because it has competencies to set the climate change and economic variables as a climate-economic model (CEM) (Auffhammer et al., 2013; Pindyck, 2013; Nelson et al., 2014; Dell et al., 2014). The calculated F-statistics value is compared with two sets of critical values estimated by Pesaran et al. (2001). One set assumes that all variables are $I(0)$ and other assumes they are $I(1)$. If the calculated F-statistics exceeds the upper critical value, the null hypothesis of no co-integration is rejected irrespective of whether the variable are $I(0)$ or $I(1)$. If it is below the lower critical value, the null hypothesis of no cointegration cannot be rejected. If it falls inside the critical value bands, the test is inconclusive.

\section{OBJECTIVES}

The general objective of this study is to find impacts of climate change on cocoa production and yield.

The specific objectives are:

1) To develop cocoa market model

2) To investigate the relationship between climate change and yield of cocoa

3) To estimate, forecast and simulate the level of cocoa production based on climate changes until 2020

4) To suggest policy alternative to mitigate impact of climate changes in sustaining cocoa production.

\section{METHODOLOGY}

The structure of the Malaysian cocoa model is presented in Figure 1. As it has been displayed, productions of dry cocoa beans hang on the harvested area and the yield in the corresponding sector. Besides, the yield of cocoa is predictable to be influenced by climate factors such as temperature and rainfall, technology and fertilizer price such as rubber and oil palm. Another more component of the cocoa beans supply is import which depends on the world prices of cocoa beans as well as the industrial production index in addition to the Malaysian exchange rate. 


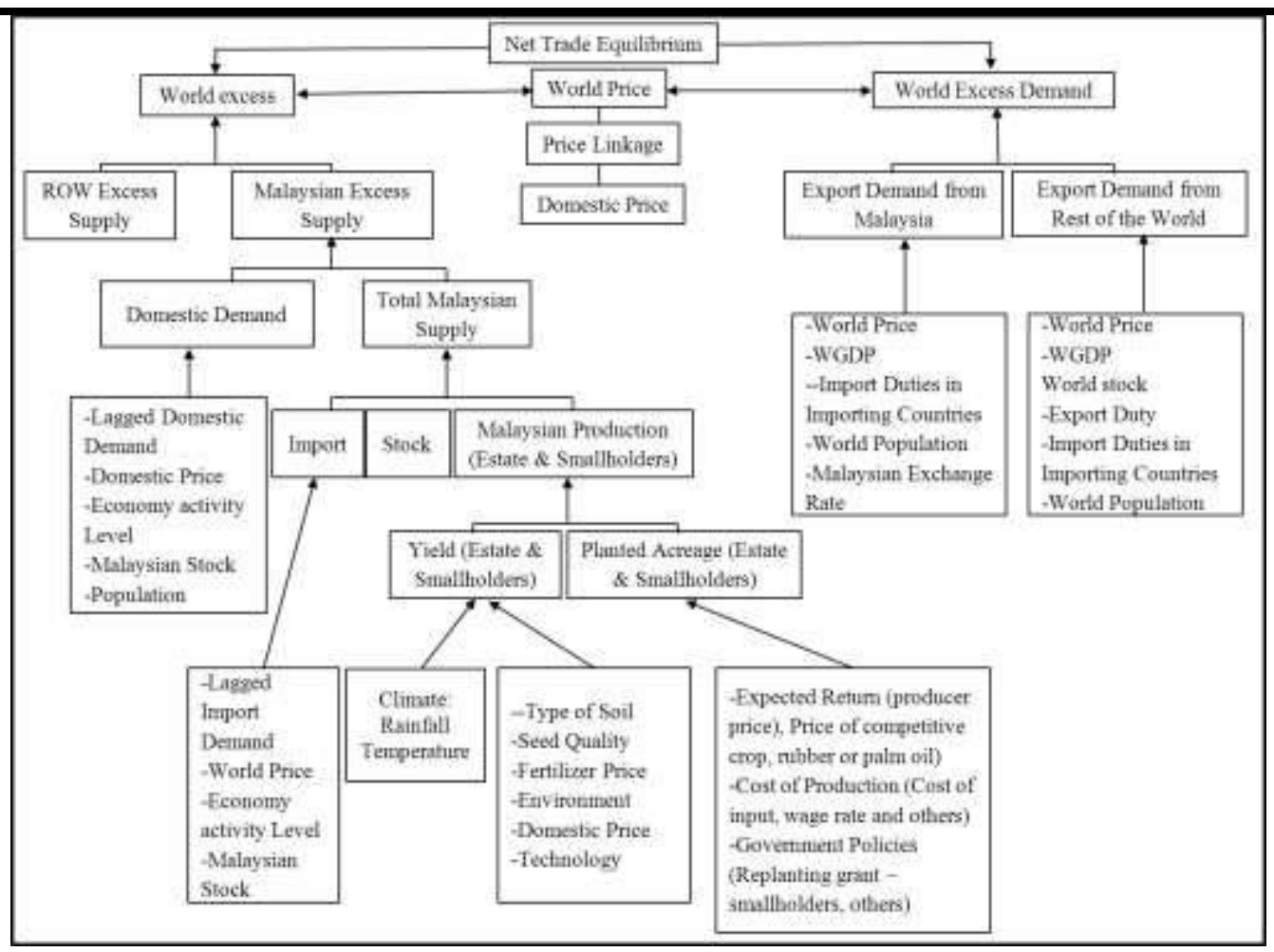

Fig.1: Conceptual Framework of Cocoa Market Model

\section{Model specification of Yield}

The yield of Cocoa Beans is dependent on its previous year's level, Climate (rainfall, temperature), the type of soil, seed quality, fertilizer and insecticide prices, and the environmental condition in addition to advancement in technology represented by a time trend.

The yield of cocoa beans Malaysia in can be presented as follows:

CBYDMY $_{t} \quad=\quad f\left(F T P_{t}\right.$, RAIN $_{t}$, TEMP $_{t}$, trend $)$

Where;

\begin{tabular}{|c|c|c|}
\hline $\begin{array}{l}C B Y D M Y \\
\text { (tonne/hectare) }\end{array}$ & $=$ & Cocoa Bean yield in Malaysia \\
\hline FTP & $=$ & Fertilizer price (RM/tonne) \\
\hline RAIN & $=$ & Average annual Rainfall ( $\mathrm{mm})$ \\
\hline $\begin{array}{l}\text { TEMP } \\
\left({ }^{\circ} \mathrm{C}\right)\end{array}$ & $=$ & Average annual Temperature \\
\hline $\begin{array}{l}\text { Trend } \\
\text { technology }\end{array}$ & $=$ & Trend dummy proxy for \\
\hline & $=$ & Time period \\
\hline
\end{tabular}

\section{Diagnostic Tests}

This study applied ARDL model and it has to adopt the Unit test (Table 1), ARDL bounds test (Table 2), and a series of diagnostic tests and stability test. Cocoa model should be validated through historical simulation. The model is selected on the basis of the Schwartz-Bayesian Criteria (SBC) and Akaike's Information Criteria (AIC) (Table 3).All the results of simulation will compare and contrast with the actual data. The closeness and deviation of the estimation results and actual values are scaled by
Root Mean Square Error (RMSE), Root Mean Square Percentage Error (RMSPE), and U-Theil inequality coefficient (Table 4). The results indicate the absence of any instability of the coefficients because the plot of the CUSUM and CUSUMSQ statistic fall inside the critical bands of the $5 \%$ confidence interval of parameter stability (Figure 3, 4).For the out-of-sample validation purposes, the endogenous variables are projected based on the actual values of exogenous. The comparison results in out-of-sample are shown in Table 5.

\section{SIMULATION MODEL}

In order to forecast and simulation of the commodity model, we determined 2014 as a base year. According to the Kwan Kok Foo (2010) it has two main methods which call Regional Climate Model (RCM) can produce reasonably appropriate projections to be used for climatescenario generation in country-scale.Based on this information this study has been considered three scenarios:

1. First Scenario, Rainfall changes: Based on rainfall changes in Malaysia in 2020 which will increase $+6 \%$ more than normal trend

2. Second Scenario, Temperature changes: Based on temperature changes in Malaysia in 2020 which will increase $+1.15^{\circ} \mathrm{C}$ more than normal trend

3. Third Scenario, Scenario 1 and 2 combined together 


\section{RESULTS AND DISCUSSION}

In Table 3, the Climate Cocoa Yield equation was determined by the technology trend $(\mathrm{T})$, lagged one and two year annual yield adjusted $\left(\mathrm{CBYDMY}_{\mathrm{t}-1}, \mathrm{CBYDMY} \mathrm{t}_{\mathrm{t}}\right.$ 2) and cocoa farm price (RCBFP), Fertilizer price in current and previous year (FTP, FTP $\left._{t-1}\right)$, rainfall (Rainfall) and temperature (TEMPER). The empirical results show that all climates the determinant variables (rainfall and temperature) have been estimated positive sign and rainfall statistically is significant at $10 \%$ significance level, but temperature is statistically insignificant. The results are supported by Just in a Oluyemisi Lawal and
Omonona, (2014), Omolaja et al. (2009) Oyekale et al. (2009). In addition, Farm price and trend are estimated positive sign however, statistically is not significant. Furthermore, fertilizer price has negative impact and the yield especially in lagged one is statistically significant at $5 \%$ level. The values of climate coefficients (rainfall and temperature) convey that they have a solid impact on cocoa yield and it displays that, if the temperature increase by $1 \%$ then coca yield would have increase $1.96387 \%$ and if the rainfall increase by $1 \%$ the yield will enhance $0.578657 \%$.

Table.1: Augmented Dickey Fuller(Unit Root) Test Results

Variable Augmented Dickey Fuller

Stationary

Level

First Difference

\begin{tabular}{lllllll} 
& $\begin{array}{l}\text { Constant Without } \\
\text { Trend }\end{array}$ & $\begin{array}{l}\text { Constant With } \\
\text { Trend }\end{array}$ & $\begin{array}{l}\text { Constant Without } \\
\text { Trend }\end{array}$ & $\begin{array}{l}\text { Constant With } \\
\text { Trend }\end{array}$ & I(0)/I(1) \\
\hline FTP & $-2.767618^{*}$ & $-3.730227 * *$ & $-7.702798^{* * *}$ & $-3.191559 * *$ & $\mathrm{I}(0)$ \\
RAINFALL & $-4.021853 * * *$ & $-4.135785 * *$ & $-4.287250 * * *$ & $-4.168478 * *$ & $\mathrm{I}(0)$ \\
TEMPRATURE & -0.33788 & $-6.269207 * * *$ & $-8.263086 * * *$ & $-7.951693 * * *$ & $\mathrm{I}(1)$ \\
CBYDMY & -1.942392 & -2.270397 & $-4.521666^{* * *}$ & $-4.478893 * * *$ & $\mathrm{I}(1)$ & $\mathrm{I}(0)$ \\
RCBFP & $-2.740792 *$ & -2.574133 & $-6.206393 * *$ & $-6.322402 * * *$ & \\
\hline
\end{tabular}

Table.2: ARDL Bound Test of Long-Run Cointegration

\begin{tabular}{llll}
\hline Equation & Lag & F-statistic & Wald test (Fs) \\
Cocoa: CBYDMY= f(FTP, RAIN, TEMP, RCBFP) & 3 & $14.4560 * * *$ & $16.18206 * * *$ \\
\hline
\end{tabular}

Table.3: The ARDL Results of Climate Cocoa YieldModel (CBYDMY)

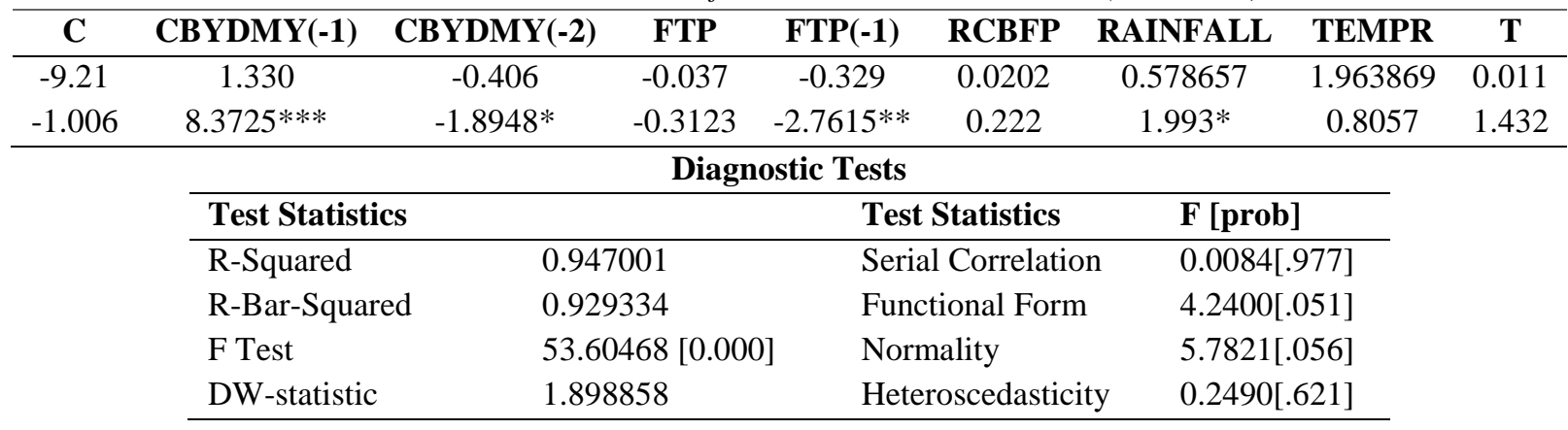

Table.4: The Summary Results of the Validation Tests

\begin{tabular}{lllllll}
\hline Endogenous & RMSE & MAE & $\mathbf{U}^{\mathbf{T}}$ & $\mathbf{U}^{\mathbf{B}}$ & $\mathbf{U}^{\mathbf{V}}$ & $\mathbf{U}^{\mathbf{C}}$ \\
\hline Cocoa LCBYDMY & 0.183943 & 0.141889 & 0.173712 & 0.008493 & 0.027477 & 0.964030
\end{tabular}

Note: $* * *, * *$, and $*$ denote significant at 1\%, 5\%, and 10\% significance levels, respectively.

Note: $R M S E=$ Root Mean Squared Error; MAE = Mean Absolute Error; $U^{T}=$ Theil Inequality Coefficient; $U^{B}=$ Fraction of error due to bias; $U^{V}=$ Fraction of error due to variance; $U^{C}=$ Fraction of error due to covariance.

Table.5: The Summary Results of the Validation Out of the Sample Test

\begin{tabular}{lll}
\hline Endogenous & RMSPE (\%) & $\mathbf{U}^{\mathbf{T}}$ \\
\hline Cocoa LCBYDMY & 18.93484 & 0.107331 \\
\hline
\end{tabular}

Note: $R M S P E=$ Root Mean Squared $\overline{\text { Percentage Error; } U^{T}=\text { Theil Inequality Coefficient }}$ 
Figure 2 shows the simulation results for cocoa yield under the three scenarios (scenario 1, 2 and 3). All projections are between the periods $(2015-2020)$. In scenario 1 (the projected changes in rainfall), cocoa yield is expected to decline from 0.148 tonne per hectare (t/ha) in 2015 to $0.143 \mathrm{t} / \mathrm{ha}$ in 2020 . The average trend compared to the baseline is positive and expected to develop by $+3.83 \%$ annually. In scenario 2 (the projected changes in temperature), cocoa yield is expected increase from $0.149 \mathrm{t} / \mathrm{ha}$ in 2015 to $0.155 \mathrm{t} / \mathrm{ha}$ in 2020 . The average trend compared to the baseline is positive and expected to increase by $+1.76 \%$ annually. Similarly, in scenario 3 (the projected simultaneous changes $(+5 \%)$ and $(+2 \%)$ in rainfall and temperature respectively), cocoa yield is expected to increase from $0.154 \mathrm{t} / \mathrm{ha}$ in 2014 to $0.189 \mathrm{t} / \mathrm{ha}$ in 2020 . The average trend compared to the baseline is also positive and expected to develop by $+6.06 \%$ annually. Finally, the results revealed that the overall trend is positive and climate change will also have positive impacts on the industry.

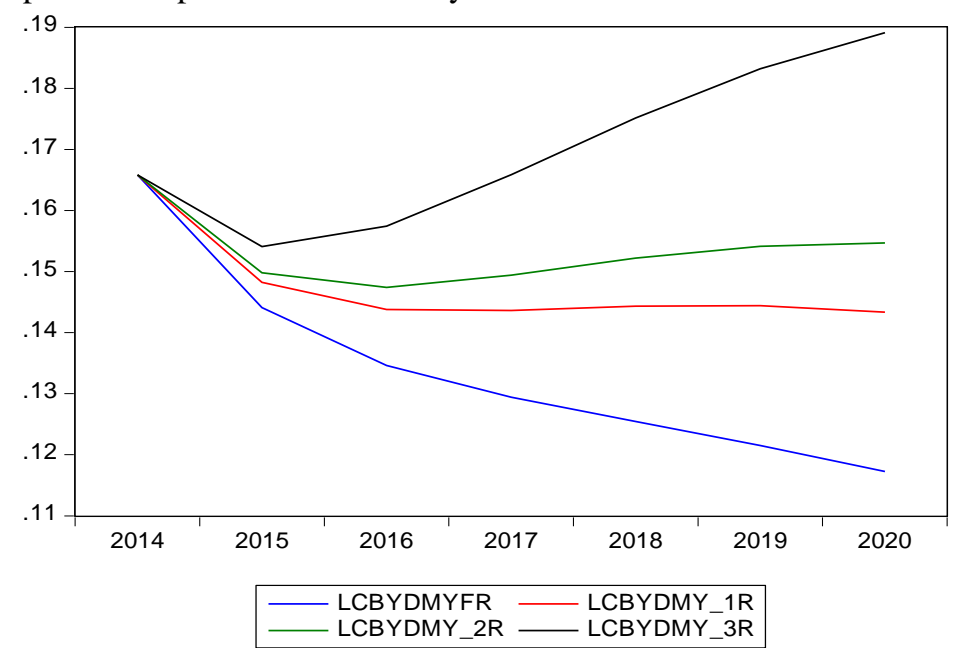

Fig.2: Simulation Results of Cocoa Yield Scenario1, 2, 3 and Base line

\section{CONCLUSION}

Cocoa represents one of the commodities that will take central role in the per capita gross national production in the coming years. Based on the result of the study, cocoa is expected to be an important commodity in the economic development of the agricultural sector. The findings from the research indicate that changes in temperature and precipitation will have no negative impact on cocoa yield in the coming years. The production trend is positive and the projected increase in temperature and rainfall will lead to about $6.06 \%$ rise in yield annually. Thus, investment in this sub-sector can be very effective in increasing the commodity's GDP share of the agricultural sector. With regards to the operational experience of the farmers in this sub-sector, it can become one of the most important commodities in Malaysia.

\section{REFERENCES}

[1] Auffhammer, M., Hsiang, S. M., Schlenker, W., and Sobel, A., 2013.Using weather data and climate model output in economic analyses of climate change. Review of Environmental Economics and Policy, ret016.

[2] Azhar, I., 2007. "The Ways towards Sustainability of Cocoa Industry in Malaysia", presentation at the ICCO Round Table on A Sustainable World Cocoa Economy, International Conference Centre Accra, Ghana, 3-6 October 2007.

[3] Corley, R.H. V., 1967. Yield potential of plantation crops. Better Crop Intl. 2(2):10-12.

[4] Dell, M., Jones, B. F., and Olken, B. A., 2014. What do we learn from the weather? The new climateeconomy literature. Journal of Economic Literature, 523, 740-798.

[5] Department of Statistics Various issues (2010-2015). National Accounts Time Series Data. Retrieved at http://www.statistics.gov.my/portal/download_Econ omics/files/DATA_SERIES/2009/Bab_ 1Akaun_Negara.pdf

[6] Department of Statistics Malaysia (DOS), 2016.

[7] Hameed, A. A. A., and Arshad, F. M, 2013.Assessing the impact of increasing planted area on the Malaysian cocoa industry.

[8] International Cocoa Organization (ICCO), 2007.Quarterly bulletin of cocoa statistics. Vol. XXXIII, No. 1, Cocoa Year 2006/2007.

[9] JustinaOluyemisiLawal, Bolarin Titus Omonona, 2014. The effects of rainfall and other weather parameters on cocoa production in Nigeria.Comunicata Scientiae 54: 518-523, 2014. African Crop Science Journal, Vol. 17, No. 1, pp. 41 -48 .

[10] Kwan Kok Foo, 2010. Climate Prediction and Information for Decision Making in Malaysia, APEC Climate Symposium 2010, APEC Climate Center APCC, Busan, Korea, 20 -24 June 2010.

[11]Lee, M. T. and Chong, T. C., 1987. High yielding cocoa plots - A case study. SASS seminar on Palm Kernel Utilization and Recent Advances in Cocoa Cultivation. 11-13 June, 1987.

[12] Malaysia Cocoa Board (MCB), 2015. Malaysian Cocoa

Board.http://www.koko.gov.my $/ \mathrm{km} / \mathrm{getfile} \cdot \mathrm{asp} ? \mathrm{id}=$ 2530I

[13] Malaysian Cocoa Board (MCB), 2007.Malaysian cocoa monitor. Vol. 16, No. 1, June 2007.

[14] MohdYusof A. S., Lamin, K., Lee, M. T. and Rosman, R. 1998. High yielding cocoa plots in Peninsular Malaysia - A case study. Proceedings of the Malaysian International Cocoa Conference, 1998. 
[15] MOPICO, 2010. Ministry of Plantation Industries and Commodities (MOPIC0)(2010) Statistics on Commodities 2010

[16] Nelson, G. C., Mensbrugghe, D., Ahammad, H., Blanc, E., Calvin, K., Hasegawa, T. and Lampe, M., 2014. Agriculture and climate change in global scenarios: why don't the models agree. Agricultural Economics, 451, 85-101.

[17] Omolaja S. S., Aikpokpodion P., Adedeji S. and Vwioko D.E., 2009. Rainfall and Temperature Effects On Flowering and Pollen Productions in Cocoa. Plant Breeding Group, Cocoa Research Institute of Nigeria, PMB 5244, Ibadan, Nigeria.

[18] Oyekale A.S., Bolaji M.B. and Olowa O.W., 2009.The Effects of Climate Change on Cocoa Production and Vulnerability Assessment in Nigeria.Medwell Agricultural Journal, Volume: 4, Issue: 2, Page No.: 77-85.

[19] Pesaran, M. H., and B. Pesaran, 1997.Working with Micofit 4.0: Interactive Econometrics Analysis. Oxford University Press, Oxford.

[20] Pesaran, M. H., Shin Y. and Smith R. J., 2001. Bounds Testing Approaches to the Analysis of Level Relationships.Journal of Applied Econometrics 16,289-326.

[21]Pindyck, R. S., 2013. Climate change policy: What do the models tell us? Journal of Economic Literature, 513, 860-872.

[22] RamleKasin, 2012. Report Malaysian Cocoa Board.

[23] Kenneth Ofori-Boateng, Baba Insah, (2014). The impact of climate change on cocoa production in West Africa", International Journal of Climate Change Strategies and Management, Vol. 6 Issue: 3, pp.296-314

[24]JUSTINA O. LAWAL and LEO A. EMAKU, 2007.Evaluation of the effect of climatic changes on Cocoa production in Nigeria:Cocoa research institute of Nigeria (crin) as a case study. Cocoa Research Institute of Nigeria, P.M.B. 5244, Ibadan, Nigeria.African Crop Science Conference Proceedings Vol. 8.pp. 423- 426.

[25] NwaJesus Anthony Onyekuru and Rob MarchantYork, 2016.Assessing the economic impact of climate change on forest resourceuse in Nigeria: A Ricardian approach. Agricultural and Forest Meteorology 220 (2016) 10-20. (Institute for Tropical Ecosystems (KITE), Environment Department University of York, University Road, York YO10 5DD, UKa)

[26] Statistics,

2016.http://www.statista.com/statistics/263855/coco a-bean-production-worldwide-by-region/

[27] World Cocoa Foundation, 2015.http://www.worldcocoafoundation.org/wpwww.ijeab.com
content/uploads/Cocoa-Market-Update-as-of3.20.2012.pdf

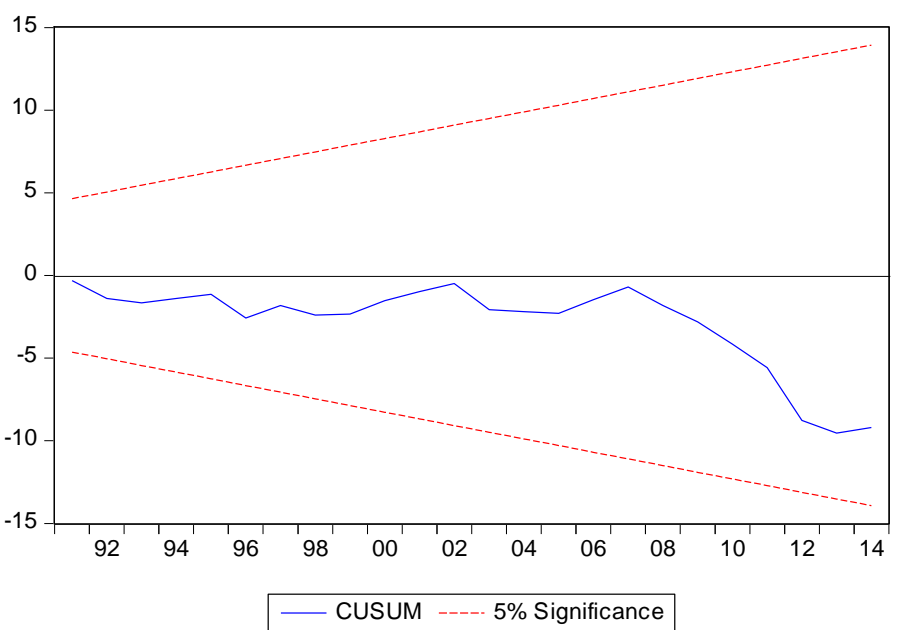

Fig.3: Cusum Test of Cocoa Yield Model

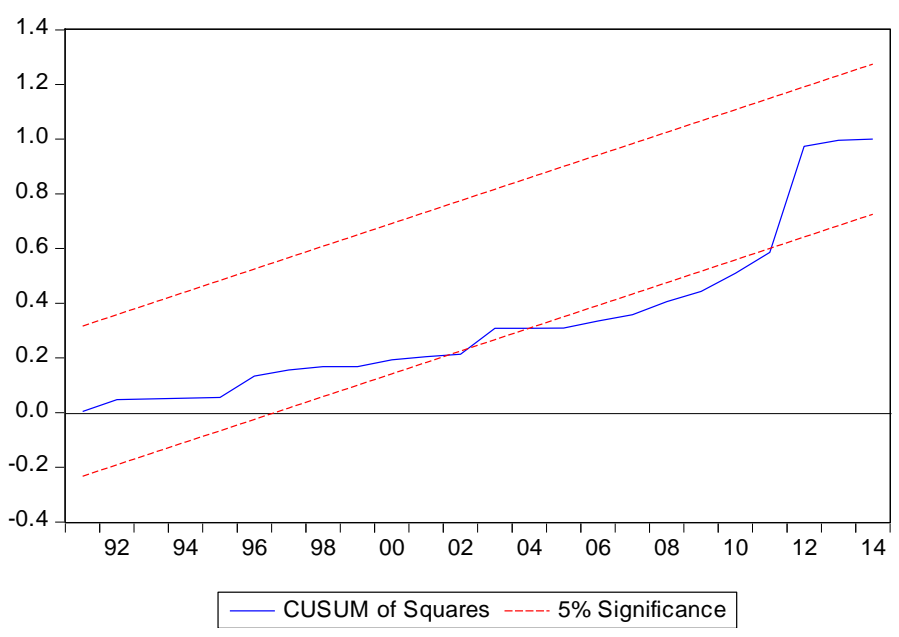

Fig.4: Cusum of Square Test of Cocoa Yield Model 